\title{
Job losses for cancer scientists at Ludwig institutes
}

\section{London}

WITH five new branches to its credit, the somewhat impenetrable Ludwig Institute for Cancer Research is closing down four old branches. About 80 scientists in Britain, Canada, Australia and Switzerland are affected. Members of at least two of the doomed branches are angered by the decisions, which fly in the face of scientific reviews of their work and have not been adequately justified.

The most recent, and smallest, of the branches to be given notice of closure is in Cambridge, England. When the branch's director departed two years ago, the Zurich-based Ludwig Institute decided against closing the branch and gave sixyear contracts to its staff. Perhaps for lack

\section{NASA's old boot \\ Washington}

THE National Aeronautics and Space Administration (NASA) announced this week that the problems uncovered by the failure of the space shuttle booster last month (see Nature 331, 2; 1988) should only delay the next flight by $6-10$ weeks, moving the launch to the middle of August. While investigations continue into the failure NASA is planning to return to an earlier design of the offending part.

The carbon-coated boot which protects the movable joint where the nozzle is attached to the rocket had been altered between last August's test, which was successful, and December's, which was not. But in the August firing, the nozzle was gimballed through an angle of only four degrees, compared to the seven-degree swivel applied in December, and it is therefore not clear whether the earlier design is actually any more robust. NASA now believes the major failure of the boot occurred after the test firing.

In the meantime, engineers at MortonThiokol, the manufacturer of the booster, have denied newspaper stories that an additional flaw was found after the December test. The nozzle assembly is sealed to the booster casing by three $\mathrm{O}$ rings, and there were reports that damage had been discovered in this joint. But a spokesman for Morton-Thiokol says that although some hot gases got past a simple adhesive strip, the O-rings were not breached.

The demands being made of the redesigned booster are considerably more strenuous than those originally required before the first shuttle flew, and there has been speculation that the kind of problem that occurred in December's test might have happened during a previous flight without being noticed. David Lindley of space, a new director has not been found. Plans are afoot, however, to solve the space problem and set up an expanded Cambridge branch of the Ludwig in 1990. Despite positive review of their programmes of research, the three senior staff of the existing branch were given one year's notice, extended on appeal to two years, and have not been offered employment in the proposed new branch.

About 20 scientists, under Dr Bernd Groner, are affected at the Bern branch, set up only four years ago to focus on the molecular and cellular biology of breast cancer, as well as its therapy. The staff were given standard five-year contracts but, says Groner, it was his clear understanding that the contracts would be renewed given a positive scientific review. Without that assurance, says Groner, it would not have been worth building up the branch. A very positive review was notched up late in 1985. A further review was scheduled for early this year but was forestalled by the December decision to close the branch by the end of this year, a period of notice that Groner considers much too short for his staff to find adequate positions and funding in Switzerland. The only official indication of a reason for closure was that space was inadequate, at least for expansion. A problem had indeed arisen with the plan to move the branch into a new building being planned at the hospital to which it is attached, but there was no foreseeable problem in continuing in the existing space.

One-year notices of closure were also issued late last year to the Toronto and Sydney branches. The latter, directed by Dr M.H.N. Tattersall, has concentrated on studies of metastasis and resistance to chemotherapy. In Toronto, experimental and epidemiological studies on the causes and prevention of colon and breast cancer have been pursued under the direction of Dr W. Robert Bruce. The Toronto branch was founded in 1981 and the contract was extended in 1986. A statement issued by the Ludwig says that the additional years were provided for the completion of the research programme which will have been achieved by the end of 1988 .

News of the apparently cavalier closure of at least two of the four branches has created concern among the staff of recently opened branches in London, Montreal, Stockholm and Uppsala. But the concern is counterbalanced by praise for the quantity and quality of support available for the new ventures. Moreover, the director of one new branch professes lack of concern. "It is the Ludwig"s right to make whatever decisions it wishes; unfortunately it is not its style to explain why", he says, adding that scientists need to become used to this style of employment and that a year is sufficient time for good researchers to find alternative employment.

Many of those involved with Ludwig affairs were prepared to say that it was not necessarily right to deal with the scientific staff in such an abrupt and insensitive way. Some suggested that the decisions were linked to an evolution of policy reflected by the recent appointment of Dr Richard Reitemeier and a new chairman of the board of directors. The possibility that the institute has over-extended itself financially with the new branches tends to be discounted. The institute's budget, which amounts to more than $\$ 30$ million a year, is derived from assets provided in 1974 by Daniel K. Ludwig, a reclusive US billionaire, whose fortune is derived from shipping interests.

Peter Newmark

UK threat to

\section{nature reserves \\ London}

BRITISH conservationists have reacted with alarm to revelations this week that the government is to examine ways of selling state-owned National Nature Reserves (NNRs). The Nature Conservancy Council (NCC), a nominally independent state-funded body which maintains and manages NNRs and advises the government on conservation policy, has been asked to extend a routine review of its assets to include an investigation of the feasibility of selling NNRs. Mr Nicholas Ridley, Secretary of State at the Department of the Environment, which this year will provide the NCC with $£ 36.5$ million as grant-in-aid, has responded defiantly to the resulting public clamour.

Of the country's 241 NNRs, covering a total of 400,000 acres, 61 are owned outright by the NCC and 48 are part-owned. The remainder are in private hands. Since 1981, NNRs have been designated as sites of special scientific interest, precluding landowners from carrying out specified "potentially damaging operations" without informing the NCC.

Precisely who would want to buy an NNR remains unclear. Voluntary conservation bodies such as the Royal Society for the Protection of Birds and the $\mathbf{4 8}$ local Nature Conservation Trusts (coordinated by the Royal Society for Nature Conservation) are adamant that they could not afford to buy or maintain NNRs.

Within the NCC there seems to be little enthusiasm for the idea. The privately expressed fear is that being the paymaster, the government could eventually have the last word if, upon receiving the results of the current review, due to be completed by the summer, it decides that the NCC did not warm to its task sufficiently energetically. 